\title{
EDUCAÇÃO PROFISSIONAL E GESTÃO EM SAÚDE: PRESSUPOSTOS TEÓRICO- CONCEITUAIS NA FORMAÇÃO DE PROFISSIONAIS DE NÍVEL MÉDIO
}

\author{
PROFESSIONAL EDUCATION AND ADMINISTRATION IN HEALTH:THEORETICAL AND \\ CONCEPTUAL PREMISES IN TRAINING SECONDARY SCHOOL PROFESSIONALS
}

Ana Lúcia Abrahão da Silva 1

Resumo O presente artigo discute os pressupostos teórico-conceituais que norteiam a matriz curricular do curso de Educação Profissional de Gestão em Serviços de Saúde ofe recido pela Escola Politécnica de Saúde Joaquim Venâncio, unidade da Fundação Oswaldo Cruz. Examina a estrutura da administração nos serviços de saúde, buscando identificar os conhecimentos essenciais para a formação do técnico de gestão em serviços de saúde, ao mesmo tempo em que dialoga com a estrutura desenhada para a educação profissional a partir da Lei de Diretrizes e Bases da Educação, de 1996. O texto finaliza com a proposta de um curso seqüencial estruturado em eixos transvers a is, objetivando formar profissionais autônomos que interajam com as mudanças propostas, principalmente de descentralização, regionalização e de democratização na área de gestão em saúde.

Palavras-chave gestão em saúde; educação profissional, nível médio.
Abstract This article discusses the theoretical and conceptual premises that serve as guidelines for the program of the Joaquim Venâncio Polytechnic Health School course on Professional Education on Administration of Health Services. The article simultaneously describes how the ad$m$ inistration of health services was assembled, seeking to identify the knowledge required of technicians in administration of health services, and debates the configuration that was designed for professional education since the promulgation of the Lei de Diretrizes e Bases da Educação (Education Guidelines and Principles Act), of 1996. In the end, the article proposes the creation of a sequential course comprised of crossing axes which seek to train independent professionals that comply with the proposed changes, especially those rega rding decentralization, regionalization and democratization in health administration.

Key words administration in health; professional education; secondary school. 


\section{Introdução}

A mudança do paradigma produtivo desenhado ao final deste milênio tem pressionado os dife rentes segmentos da sociedade a se adequarem a novas re gras sem a presença do Estado. Aposta-se no me rcado. Neste contex to, a área de educação ocupa um lugar de destaque, sendo inquirida a formular propostas que equacionem o velho dilema que está posto entre a formação propedêutica e a formação profissionalizante. Por outro lado, o setor saúde demanda a formação de profissionais que respondam por um novo modelo de ge stão para o sistema. Neste desafio, a educação profissional merece ser alvo de investigação, como uma estratégia de mudança para o modo de se organizar os serviços de saúde.

A Escola Politécnica de Saúde Joaquim Venâncio (EPSJV), unidade técnico-científica da Fundação Oswaldo Cruz, vem redimensionando a estrutura dos seus cursos desde a aprovação da Lei de Diretrizes e Bases da Educação (LDB) em 1996, promovendo mudanças na formação de profissionais de nível médio em saúde capazes de responder às exigências de um sistema único de saúde.

Neste cenário desenhado pela conjuntura das sociedades contemporâneas, o curso de Educação Profissional de Gestão em Serviços de Saúde estrutura-se a partir de competências e habilidades, articuladas nas áreas da gestão e da saúde - áreas profissionais distintas, segundo a diretriz curricular da educação profissional, parecer $n^{\circ}$ 16/99 (MEC, 1999a). Ter áreas separadas revela competências distintas, e a necessidade de desenhar conhecimentos e habilidades capazes de estruturar uma formação entre as áreas retrata, assim, uma nova área de saber para o nível médio.

Em certa medida, a legislação para a formação deste profissional, hoje, no Brasil (lei $\mathrm{n}^{\circ}$ 9.394/96, LDB) argumenta que a formação não é algo acabado, fechado; ao contrário, ela oferece a base para a capacitação em diferentes áreas e campos profissionais, organizando o conteúdo pela competência de cada profissão. Sendo assim, o caráter flexí vel da educação profissional ap resenta-se adequado para ser ajustado entre as duas áreas: gestão e saúde.

O curso de Educação Profissional de Gestão em Serviços de Saúde, foco deste artigo, possui duração de três anos, estruturados com base nas pesquisas: "Habilitação em administração hospitalar: um estudo sobre os egressos da Escola Politécnica de Saúde Joaquim Venâncio" (Abrahão, 1999a) e "Educação profissional: administrando a competência" (Abrahão, 2000). A primeira investigação objetivou a descrição do perfil do profissional de administração hospitalar formado entre 1988 e 1996 pela EPSJV, buscando reconhecer sua inserção no mercado de trabalho e a visão dos gerentes, diretores dos hospitais sobre o processo de trabalho desse profissional. A segunda investigação propôs um desenho curricular por competência voltado para as demandas na área de gestão em saúde, articulado à LDB/96 e ao pare- 
cer $n^{\circ} 16 / 99$ (que dispõe sobre a educação profissional). Ambas as pesquisas foram financiadas pela EPSJV por meio do Programa de Aperfeiçoamento do Ensino Técnico (Paetec).

Mediante a análise dos resultados das pesquisas e da experiência na coo rdenação do curso de educação profissional, desde 1996, buscou-se enfrentar metodologicamente a complexidade exigida para a formação do técnico de gestão em serviços de saúde. Foram constituídos territórios de conhecimentos, interdependentes, mas com garantia de autonomia relativa entre si, constituindo o desenho de uma grade curricular baseada nas inovações ge renciais no campo da saúde, a partir da orientação da educação profissional (decreto $\mathrm{n}^{\circ}$ 2.208/97). A opção adotada para a formação é um curso seqüencial estruturado em eixos transversais de conhecimento. Eixos transve rsais correspondem a territórios de saber que conjugam competências e habilidades-chave para a formação. Conhecimentos que transitam por todas as disciplinas possibilitando, em cada uma delas, estruturar competências a partir do saber contido nos 'territórios-eixo'. Assim, no decorrer do curso o aluno é convidado a construir um saber que toma por base territórios de conhecimento presentes no campo da gestão e da saúde.

A formação proposta pressupõe uma prática pedagógica que conjugue questões próprias da técnica e da ciência com uma formação crítica, rigorosa e humanística. Este último componente é imprescindível para a formação de profissionais numa perspectiva de romper com padrões mecanicistas, possibilitando uma melhor compreensão da sociedade e de suas diversidades.

A proposta para o profissional de nível médio, um técnico, é orientada de forma a responder às demandas eme rgentes, a partir da compreensão da estrutura dos serviços de saúde, e a articular, em seu modo de trabalho, a área meio à área fim no interior das organizações de saúde, promovendo um p rocesso de trabalho coerente com as mudanças gerenciais e a prática nos serviços de saúde.

Com o objetivo de identificar por quais territórios de conhecimento é constituído o saber do técnico em gestão, o curso examina a estrutura política e administrativa dos serviços de saúde ao mesmo tempo em que dialoga com a formação do trabalhador a partir das diretrizes presentes na LDB/96. Por fim, aceita-se o desafio e propõe-se um curso de educação profissional para técnicos de gestão em serviços de saúde.

\section{Novos arranjos para a prática da gestão}

As modificações enfrentadas pelo setor saúde nos últimos anos têm seguido a lógica da descentralização, na tentativa de aumentar a participação e a re sponsabilidade, nas três esferas de governo, com os serviços oferecidos à po- 
pulação. Delegar maior responsabilidade aos níveis periféricos do sistema tem sido uma constante no padrão da reforma sanitária.

Tais arranjos reformistas têm sido acompanhados de propostas que provocam alterações significativas na estrutura dos serviços e na condução das políticas. No caso brasileiro, segundo Almeida (1999), dois são os pólos que orientam as perspectiva reformistas, quais sejam: 1) contenção dos gastos com assistência médica, traduzida em busca por eficiência; 2) reestruturação do mix público-privalo (com a descentralização de ações e responsabilidades para o setor privado e níveis subseqüentes do governo) aliada ao aumento da participação financeira do usuário no custo dos serviços.

Dessa forma, a discussão gira em torno da maneira como o sistema e os serviços de saúde se organizam para atender aos apelos reformistas. Nessa lógica, os serviços de saúde passam a exercer função importante no processo saúde-doença, e, à medida que tais serviços se aprimoram, há uma ampliação de seu espectro de ação e uma maior abrangência na definição do problema de saúde, com relativa necessidade de capacitação profissional.

A Norma Operacional Básica (NOB) do Sistema Único de Saúde (SUS) 01/96 (portaria $n^{\circ} 2.203$ ) consolida o processo de descentralização/municipalização das ações de saúde, deixando clara a responsabilidade de cada nível de governo perante a saúde, e a gestão dos municípios passa a ter mais autonomia. Esse processo de descentralização traz consigo a preocupação com a capacidade dos profissionais de gerenciar os municípios respondendo aos pressupostos do sistema. Dessa forma, a elaboração conceitual na prática gerencial torna-se o foco de investigações e investimentos do sistema (Tanaka et al., 1999).

\section{Características da prática gerencial nos serviços}

A ciência nascida das mentes de Newton, Copérnico e Galileu Galilei, a ciência moderna, caracteriza-se pela riqueza de detalhes, pelos saberes particularizados e por questões frag mentadas do conhecimento humano e do mu ndo. Desta forma, o ganho se dá pelos detalhes, mas o ser é esquecido em favor do existir (Boff, 1997). Por muitos anos, esta ciência foi gênese de inúmeros paradigmas, entendendo-se que, por partes, como Jack (legendário assassino inglês que esquarteja suas vítimas), poderíamos resolver as inquietações que assolam a humanidade. Tais concepções reduzem o complexo ao simples, pela dificuldade de se lidar com a complexidade da qual emerge o mundo (Abrahão, 1999a).

A ciência contemporânea, a partir de estudos da física, da biologia molecular, entre outros, mostra a importância da relação entre as partes, tendendo a respeitar a totalidade e considerando os diferentes pólos (caos-cosmos e 
desequilíbrio-equilíbrio) como elementos dessa teia de relações em que se encontra o mundo. A complexidade torna-se uma característica fundamental.

Teorias funcionalistas e estruturalistas da administração científica tomam por paradigma a ciência moderna, não considerando a complexidade inerente a qualquer organização. Os conhecimentos acumulados ao longo dos anos, dentro dessa vertente mecanicista, predominantemente na área de administração, vêm esbarrando em determinados limites, ao se confrontarem com os desafios a serem enfrentados (Campos, 1997).

$\mathrm{Na}$ área da saúde, os ge storessentem, na prática, os limites de algumas dessas teorias. Nas organizações de saúde, por exe m plo, tenta-se moldar o processo de trabalho ao modo de trabalho de uma fábrica. A administração dos serviços de saúde costuma ser primitiva em sua forma de conduzir processos, pois estes ocorrem, em geral, sem planejamento e sem avaliação posterior. Para Campos (1992), o modelo ge rencial predominante no SUS tem baixa eficácia, encontrando dificuldades para atenuar a desigualdade distributiva, inerente à lógica de mercado, e para se universalizar.

Ademais, a gestão em serviços de saúde costuma apresentar-se como uma prática clientelista e de favorecimentos, fruto de uma rotina hegemônica e histórica advinda do Estado e do poder econômico dominante. Cargos, principalmente os de dire ção, são tomados como objeto de barganha; por pressão de interesses corporativos, entre outro s, são ocupados por 'indicação' e não em função da competência profissional (Dussault, 1992).

O tipo de administração em saúde predominante no Brasil foi sendo desenvolvido de forma dife rente do modelo tradicional liberal norte-americano. No Brasil, a adaptação causou certa iatrogenia ao serviço, como o excesso de burocracia, além de ter trazido características de mercado aos serviços de saúde brasileiros. Nas décadas de 1940 e 50, incorporam-se conceitos de administração científica à política nacional. Estas novidades, trazidas pela Fundação Serviço de Saúde Pública e pela Escola de Saúde Pública da Universidade de São Paulo (USP), no entanto, reforçaram a estrutura hierarquizada e de baixa motilidade gerencial da saúde pública (Campos, 1991).

Apesar da administração dos serviços de saúde ser marcada pelos preceitos e normas rígidas verticais da administração científica de Taylor e Fayol, a saúde coletiva, especificamente a área de planejamento e administração de serviços de saúde, conseguiu avançar ao longo das últimas décadas. A partir de discussões sobre os modos de entender os processos de coord enação no interior dos serviços de saúde e o modo de trabalho dos profissionais da á rea, foi possível acumular um quadro importante de propostas gerenciais. Autores brasileiros, como Gonçalves (1994), Campos (1992), Rivera (2003), Merhy (2002) e Mendes (1998), oferecem propostas para se pensar e dialogar no agir em saúde de forma diferenciada da proposta centrada somente no fator econômico, atuando e modificando o processo de gestão. 
Estas propostas provocam não só uma reflexão sobre a condução e a dinâmica da gerência no interior das organizações, como também, sobre o papel dos atores envolvidos nessa nova lógica administrativa.

É necessário ressaltar que as organizações de saúde possuem especificidades no processo de trabalho, na clientela e no produto. São organizações caracterizadas pelo fato de que tanto os poderes decisórios quanto a administração e distribuição de recursos estão dispostos entre uma parcela importante dos profissionais operacionais - médicos, enfermeiros, nutricionistas, entre outros. Estas organizações seriam, segundo Mintzberg (1995), pirâmides invertidas, por concentrar o poder na base da organização.

São inúme ros os autores que oferecem formulações teóricas sobre a estrutura e a forma das organizações. Mintzberg (1995) ex p ressa sua visão de acordo com sete configurações, que, conforme o jogo de combinações, caracterizam os dife rentes tipos de organizações. No caso da saúde, o estudo dos hospitais configura, por este olhar, uma organização do tipo profissional, embora o autor destaque que em uma mesma organização convivem todas as configurações.

As organizações do tipo profissional, segundo o autor, possuem na sua base operacional - onde de fato se dá o trabalho - profissionais altamente especializados. A atividade desenvolvida possui alto grau de autonomia, garantindo, portanto, como já mencionado, o poder na base da organização. A coordenação das ações destes trabalhadores no interior dos hospitais torna-se, assim, bastante complexa. Neste sentido, os trabalhadores sofrem pouca ou nenhuma influência interna da administração quanto ao seu m odo de trabalho.

As organizações de saúde ap resentam também uma área de apoio bem desenvolvida. São as atividades me i o, entendidas por uma grande parcela dos profissionais da base operacional como sendo ações auxiliare s, e não parceiras. Este é um fator que interfere de forma contundente no atendimento ao usuário. Os profissionais da área meio, em sua maioria de nível médio, disputam espaço dentro da organização de maneira sutil, utilizandose da parcela de poder que lhes é devida. Por exemplo, cortes nas solicitações de material feitas por estes profissionais significam falta de conhecimento da real necessidade do serviço ou excesso de burocracia, mas não é raro consubstancializarem-se num dos meios utilizados para 'medir forças' com os profissionais da área fim.

A organização de saúde tem objetivos que, na maioria das vezes, difere nciam-se dos objetivos dos profissionais nela alocados; isto, aliado à pulverização interna do poder, faz com que as metas a serem alcançadas pelas corporações profissionais se sobreponham às metas organizacionais e aos interesses dos usuários. Este mesmo exercício de poder, que dificulta o alcance dos objetivos, agrega os trabalhadores em torno de interesses corporativos. 
O fim último da organização costuma pulverizar-se, nem sempre pre valecendo a necessidade de atenção ao usuário. Como destaca Lemos (1994), os grupos de especialistas internos à organização tendem a abordar os problemas de saúde a partir da visão especializada que adquiriram ao longo de sua formação. Em função de suas especialidades, passam a ter verd a deirossubobjetivos e buscam exclusividade nos ganhos dentro da organização.

\section{Delineando a formação do trabalhador na gestão}

Nas discussões em torno da gestão em saúde, a complexidade de gerenciar/administrar é reconhecida. Vale dizer que tal complexidade está ligada a pelo menos uma dimensão: a organização do trabalho, com base em profissionais com grande autonomia em relação ao que é produzido.

A importância do investimento na formação de gestores é uma constatação que se coloca de forma mais orgânica a partir da NOB/96. Cursos de especialização são organizados como forma de contribuir para a capacitação de profissionais que possam responder de forma positiva às exigências e re sponsabilidades presentes a partir da descentralização/municipalização do sistema. Por outro lado, a formação de profissionais que operacionalizam ações em um nível intermediário no campo da gestão é ainda vista como de baixa prioridade e, portanto, não há muita ênfase no seu enfrentamento.

Como campo de experiências, a gestão em saúde tem apresentado propostas de gestão pautadas nos princípios do SUS. Se por um lado essas propostas avançam em práticas concretas de mudança no modelo de atenção, por outro revelam a necessidade de formação dos profissionais neste processo.

Contudo, as exigências e os requisitos relativos à formação do profissional que exerce funções no nível intermediário (área meio) das organizações de saúde são relativamente baixos, pois a formação exigida é a de auxiliar administrativo, sem aprofundamento das questões próprias do setor saúde. A lógica que se apresenta é a de que a formação pode ser e é adquirida na prática, no próprio local de trabalho, como algo natural e comum. Santos e Christófaro (1996) chamam a atenção para a alienação social que se produz a partir do momento em que se considera natural que o profissional dessa área da saúde passe a aprender em seu próprio local de trabalho.

"Se por um lado atendem a demandas concretas da sociedade, no âmbito da saúde, estas lhe chegam interpretadas e traduzidas enquanto tarefas a serem pontualmente operacionalizadas e cujo valor, poder e impacto se perdem na complex idade do processo e do produto do trabalho. Assim, ao mesmo tempo que são essenciais são descartáve is, fazendo-lhes se ve rem e serem vistos como cumpridores de ordens de trabalho e não como sujeitos de um trabalho a ser avaliado, re- 
conhecido e recompensado - material e socialmente — dentro das relações de trabalho e pela sociedade" (Santos e Christófaro, 1996, p. 50).

A formação educacional exigida destes profissionais é básica, sem a preocupação de se construir conjuntos específicos de conhecimentos. Ela é aliada a conhecimentos adquiridos no próprio espaço de trabalho e de acordo com a estrutura dos processos internos a cada setor e com a sua organização.Nestes casos, o aprendizado, por ser in loco, em geral desconsidera aspectos importantes do processo de trabalho global da administração em saúde, bem como a relação entre o modo de ação desenvolvido pelo profissional de nível médio e os demais profissionais que atuam nessas orga nizaçõ e s. Ressalta-se, ainda, um certo desconhecimento do rol de especificidades que delineiam as organizações de saúde e sua articulação com um sistema descentralizado e um certo despreparo no entendimento das necessidades que emergem dos processos das áreas assistenciais (Abrahão, 2000).

Assim, a formação se dá de forma pulverizada e em consonância com o setor (área da organização) em que o profissional está atuando, sem uma sistematização maior acerca das áreas de conhecimento, habilidades, instrumentos, tecnologias e necessidades centrais para o aprendizado deste ator.

Reconhece-se que a organização de saúde, estruturada hierarquicamente, é marcada pelo saber. Um saber que se consagra na hegemonia biológica, respaldada pela sociedade, em que o médico representa esse saber. Um saber que é do outro, revelando baixa autonomia no processo de trabalho do profissional de nível médio.

Campos (1992 e 1998) tem trabalhado com uma concepção distinta. Para este autor, a autonomia relativa dos médicos e de outros profissionais de saúde poderia representar uma vantagem que assegura qualidade ao trabalho em saúde. Para tanto, ele critica as tentativas de se impor controle administrativo às equipes e sugere a instituição de modificações radicais no processo de trabalho. Pretende, assim, definir claramente as responsabilidades de cada profissional. Campos advoga ainda o emprego de um novo método de gerência que, ao invés de recomendar restrições à autonomia profissional, incorporaria médicos, enfermeiros e demais profissionais em um sistema de co-governo.

Nessa lógica de autonomia profissional, a expectativa em relação à formação do técnico de gestão é que ela atenda e responda à complexidade que marca o trabalho em saúde, ao mesmo tempo que, individual e coletivamente, acompanhe e incorpore mudanças advindas do desenvolvimento técnico-científico da área da gestão em saúde, na pers pectivade intervir positivamente na assistência em saúde, mesmo que de forma indireta.

Por outro lado, o trabalhador de saúde da área meio convive com grande volume de processos, ações que compreendem, embora não de maneira aparente, um certo poder e grau de autonomia presentes no espaço de de- 
cisão das agendas, distribuição de materiais de consumo, andamento de processos de compras etc. Este processo de trabalho exercita doses sutis de um poder pouco entendido e muitas vezes desconhecido pelo próprio trabalhador e, portanto, subestimado pelos demais profissionais da área que não reconhecem a real importância dessas ações (Abrahão, 2000). Por outro lado, “(...) ex pressam o valor - material e social - desse trabalho, em cada tempo e lugar, definindo o espaço social e político dos trabalhadores de saúde na sociedade e no processo de trabalho" (Santos e Christófaro, 1996, p. 49).

Como ressaltam Santos e Christófa ro, "as práticas de saúde dependem de requisitos específicos" (p. 50). Requisitos inerentes e coerentes com a especificidade de uma área atravessada por fluxos de interesses políticos, econômicos, e pelas necessidades de saúde dos usuários.

\section{Proposta de formação}

A ap rovação das diretrizes para a educação em 1996 concretiza-se com a regulamentação, no caso da educação profissional, do decreto $\mathrm{n}^{\circ} 2.208 / 97$. Dessa forma, desde 1997, a preocupação em garantir a formação profissional tem sido tema de projetos e discussões no âmbito da educação, cuja conjuntura é marcada por pressões por produtividade e competitividade. Segundo Ferretti, a educação profissional

“(...) tem conotações diferentes, na medida em que enfatiza menos a posse dos sab e res técnicos e mais a sua mobilização para a resolução de problemas e o enfrentamento de imprevistos na situação de trabalho, tendo em vista a maior produtividade com qualidade" (Ferretti, 1997, p. 3).

A contextualização e a interdisciplinaridade estão presentes nos conhecimentos utilizados para o uso cotidiano da profissão e da prática pedagógica. Ambos são fundamentados em competências, presentes na LDB/96 e na Constituição Federal de 1988, inspiradas por valores estéticos, políticos e éticos. O que de certa forma, se assim podemos entender, rompe com a idéia de 'naturalização' da formação em serviço para o nível médio, na medida em que considera fundamentais os valores políticos, éticos e estéticos na educação profissional.

A proposta de organizar a formação por competências de certa forma cumpre o artigo 1 da LDB, onde se lê "vincular-se ao mundo do trabalho e à prática social" (Brasil, 1996). Dessa forma, as habilidades específicas e as competências de cada formação são orientadas pelo processo de trabalho.

Contudo, no Brasil, são poucas as experiências de formação profissional por competência e o conceito é de difícil definição, ocasionando uma verda- 
deira celeuma acadêmica. De acordo Tanguy e Ropé (1997), uma das características da competência é ser inseparável da ação.

\footnotetext{
“Nos assuntos come rciais e industriais, a competência é o conjunto de conhecimentos, qualidades, capacidades e aptidões que habilitam para a discussão, a consulta, a decisão de tudo o que concerne seu ofício (...) Ela supõe conhecimentos fundamentados (...). Geralmente, considera-se que não há competência total se os conhecimentos teóricos não forem acompanhados das qualidades e da capacidade que permitam executar as decisões sugeridas"' (Tanguy e Ropé, 1997, p. 53).
}

A despeito das discussões que giram em torno deste conceito, buscando melhor clareza em sua definição, o que se tem verificado é a necessidade de ofe recer uma formação que articule em seu interior dife rentes abord agens teóricas e disciplinares, que dêem conta das necessidades das duas áreas profissionais que estruturam a formação do trabalhador em gestão — saúde e gestão. Estas discussões tomam corpo quando apreendidas através do campo da saúde coletiva, o que possibilita perceber o fenômeno interdisciplinar como uma forma de operar o saber, permitindo a construção de conhecimentos que capacitem o futuro técnico de gestão no acompanhamento das permanentes mudanças operadas no processo de trabalho gerencial dos serviços de saúde.

\section{Pressupostos teóricos}

Além de desenvolver linhas teóricas que conseguissem um olhar diferenciado para os 'detalhes', a gerência em saúde preocupa-se com a reforma do modelo de gestão da área pública, pautada na descentralização, no planejamento e na avaliação. Para Campos (1992), o modo de gerenciar a saúde deve considerar o SUS como fator estratégico para a reforma sanitária, desde que se entenda este gerenciamento como instrumento de exercício de poder democrático.Neste sentido, poder-se-ia utilizá-lo para estímulo à criatividade e com objetivo de formar trabalhadores que transformem a realidade atual, garantindo o acesso à saúde e às tecnologias que auxiliam a humanidade a ter uma vida mais saudável.

É inegável que parte da formação desse trabalhador de saúde reside nos conteúdos das disciplinas que compõem o ensino médio (antigo segundo grau), saberes capazes de garantir as informações necessárias à compre ensão e leitura dos novos códigos simbólicos que se inscrevem nas mudanças tecnológicas e sociais (Abrahão, 2000).

Outro aspecto importante na formação é "potencializar as possibilidades de qualidade dos serviços que prestam e legitimá-los, social e tecnicamente, na 
produção de saúde e na sociedade" (Santos e Christófa ro, 1996, p. 52). Para tanto, a aquisição de conceitos relativos ao processo de trabalho em saúde é fundamental. Busca-se no interior do curso de técnico de gestão em saúde detalhar as várias facetas deste processo como: a integração/interação dos p rofissionais de saúde e suas atividades específicas; o cuidado e o modelo de atenção; as relações entre o usuário, a instituição e os profissionais; o percu rso e os entraves encontrados pelos usuários, no interior das organizações de saúde, que são elementos/conhecimentos legítimos e presentes no trabalho em saúde. Elementos que articulam e são atravessados a todo tempo pela autonomia e pelo poder. Estrutura básica para a formação de um ator comprometido com a qualidade da produção dos serviços de saúde.

Vale ressaltar que esses conhecimentos estão inscritos no campo da saúde coletiva, especificamente na área de planejamento e administração de serviços de saúde. Os saberes adquiridos a partir deste campo possibilitam a formação de um núcleo que congrega a discussão sobre o processo de trabalho em saúde, o quadro sanitário brasileiro, a informação em saúde e as políticas de saúde, conhecimentos que formam a base para o trabalhador de nível médio na área de gestão em saúde.

Expandindo o núcleo de saber, na ve rdade ampliando o campo de ação, o saberrelativo ao cotidiano de uma organização de serviços torna-se fundamental. O conhecimento deste trabalhador começa a ser inscrito em um novo território. Saberes da área da informática, de planejamento, de orçamento e do sistema de abastecimento são de extrema relevância nesse contexto de mudanças tecnológicas e de rearranjos na estrutura produtiva (Abrahão, 2000).

A informação como saber integra este território sob dois aspectos. É suporte para as decisões ge renciais e tem capacidade de estreitar as relações no interior dos serviços que compõe a organização. A articulação entre os serviços derivada deste último aspecto é empregada por alguns modelos gerenciais da saúde coletiva com objetivo de possibilitar o diálogo entre as unidades, uma estratégia de negociação dentro de uma perspectiva democrática e de co-gestão.

Ainda sobre a utilização da informação, explorar a capacidade crítica dessa análise, tornando o diálogo uma forma de disseminação dos dados para o interior da organização,éum enfoque extre ma mente necessário à formação de profissionais que irão desenvolver sua vida profissional na área da saúde. Nesse sentido, a formação deve passar pelo espaço coletivo e democrático das práticas e ser orientada na perspectiva de construção conjunta do saber. Assim, objetiva-se ampliar o conhecimento do profissional a re speito das ações desenvolvidas no setor saúde, acentuando-se a necessidade de uma boa qualificação e integração junto à área fim, reforçando o elo, do processo de trabalho do técnico, entre as áreas meio e fim. 
Explorar a autonomia do processo de trabalho deste profissional significa construir espaços para a formação de sujeitos coletivos comprometidos com a defesa da vida e a transformação social. Assim, toma-se o conceito de sujeito trabalhado por Campos (2000), segundo o qual o sujeito e os coletivos organizados para a produção estão em constante devir. Sujeitos são seres constituídos de elementos internos e externos e os coletivos organizados perfazem uma rede de relações entre os sujeitos e destes com o contexto.

Esta permanente interprodução abarca três regiões: particular, unive rsal e singular. A região particular faz parte da dimensão interna representada pelo plano do desejo, dos interesses e dos determinantes biológicos. A região universal faz parte da dimensão externa da constituição do sujeito. O autor a define como um plano em que a presença dos valores e necessidades sociais revela constrangimentos ao ser, com pequena influência a médio e longo prazo. E por último a singular, uma região intermediária às dimensões interna e externa, um espaço em que a instituição do novo seria possível, pela multiplicidade de sínteses que o sujeito produz mediante a influência e pressão dos planos anteriores (Campos, 2000).

Nessa pers pectiva, a região singular - apontada pelo autor como lugar onde a síntese do interno com o externo se ap resenta como um espaço em que a autonomia e a prática da negociação seja possível, possibilitando o diálogo entre o desejo e a necessidade social - representa o plano eleito para a construção de um profissional de nível médio na área da gestão em serviços de saúde, com potencial para operar um novo modo de trabalho entre as áreas meio e fim das organizações de saúde. Nesse sentido, a formação caminha para constituir-se nesse espaço de interseção, promovendo linhas de fuga e criando meios favoráveis para a base pedagógica do curso.

De outra forma, o plano singular é percebido e estimulado no processo de trabalho desse profissional. Assim, a articulação entre a área fim e a área meio das organizações de saúde torna-se possível pela definição de um espaço de negociação, social e política, para o técnico em gestão no seu processo de trabalho.

\section{Proposta de curso de educação profissional estruturado em eixos transversais}

À viabilização de um território para a formação do técnico de gestão em serviços de saúde se aplica a noção de rede, pois o tratamento em rede se coloca como uma nova forma de percepção da estrutura técnica e da relação humana, permitindo que a intervenção em saúde, tema debatido por uma série de setores da sociedade, possa ser estudada sobre a forma da multiplicidade, 
face aos dife rentes fatores que afetam as condições de vida saudável da população e que, portanto, não podem ser tratados de maneira uniforme. Da mesma forma, discursos administrativos dão enfoque a modos ge renciais reticulares. Enfim, a formação em rede permite a mobilização/trânsito entre núcleo e campo durante a formação do técnico.

A temática da rede, segundo Konh (1994), conduz ao estudo das relações entre indivíduos e entre indivíduos e instituições. Para este autor, uma rede se caracteriza pelo “(...) exe rcício de poder, de modos de regulação e de repartição de energias, de extensão e de fronteiras do território geográfico, administrativo e social" (p. 2).

Nessa perspectiva, a formação se aproxima do núcleo saúde em três vertentes: saúde, sociedade e cidadania, geografia espacial e política do quadro sanitário brasileiro, além da produção e disseminação de informação em saúde. Contudo, há saberes transversais que estariam presentes em todo mome nto de formação do aluno. Portanto, a base dessa formação perpassa a saúde, a sociedade e a política e, por último, a competência no campo da administração, que amplia o núcleo, construindo um campo de atuação para o trabalhador em gestão (Abrahão, 2000).

A gradação no desenvolvimento do conhecimento parte do mundo global do trabalho/mercado, conhecendo e explorando a sociedade nesse meand ro e retomando alguns momentos históricos que marcaram a humanidade. Assim, amplia-se o campo de conhecimento e passa-se a interagir com saberes da ciência e com as tecnologias em saúde, administração, planejamento e serviços denominados gerais.

De certa forma, a proposta curricular, a partir dos eixos transversais, mobiliza valores fundamentais na formação de um profissional autônomo quando possibilita a discussão em torno da concepção de sujeito, abrindo espaço para interrogações e contradições afeitas a este conceito.

A preocupação em romper com a 'naturalização' imposta pela crença de que profissionais de nível médio se formam em serviço, e a conseqüente alienação que ela re presenta, é problematizada em cada território de forma gradativa e com a possibilidade de construir um território de conhecimento próprio para o nível médio na área de gestão em serviços de saúde.

Dessa forma, os eixos transversais balizam a formação.Este conceito de eixos transversais conduz a idéia de saberes que estão presentes em todas as et apas da formação, ao mesmo tempo em que configura a base estruturante do conhecimento neste novo território.

Assim os eixos transversais, como um fluxo, percorrem a formação do técnico permeada por competências. O Quadro 1 apresenta os eixos, as ementas e as competências do curso de Educação Profissional de Gestão em Serviços de Saúde. 
Quadro 1

Exostransversais, ementas e competências do curso de Ed u cação Profissional de Gestão em Serviços de Saúde

\begin{tabular}{|c|c|c|}
\hline Eixos transversais & Ementa & Competências \\
\hline $\begin{array}{l}\text { Administração e } \\
\text { planejamento em } \\
\text { serviços de saúde }\end{array}$ & $\begin{array}{l}\text { Compreende disciplinas que estudam } \\
\text { a administração, o suporte logístico, } \\
\text { a produção e a prestação de serviços } \\
\text { em dife rentes setores econômicos e } \\
\text { em organizações públicas e privadas. } \\
\text { As atividades de administração em } \\
\text { saúde caracterizam-se por se basearem } \\
\text { nas especificidades no campo da } \\
\text { saúde coletiva. }\end{array}$ & $\begin{array}{l}\text { Identificar as estru tu ras organizativas nas } \\
\text { organizações e serviços e relacioná-las } \\
\text { com os processos de gestão específicos. } \\
\text { Interp retar resultados de estudos } \\
\text { de inovação na gestão em saúde } \\
\text { utilizando-os no processo trabalho. }\end{array}$ \\
\hline
\end{tabular}

Geografia espacial e política do quadro sanitário brasileiro

Produção e

disseminação de

informação em saúde

Ciência e tecnologia

em saúde

Saúde, sociedade e cidadania

\section{Abrange as dimensões conceituais} que estruturam o sistema de saúde brasileirq ultrapassando a ênfase na ausência de doença como requisito para a obtenção da saúde.

Compreende as possibilidades de utilização de dados para trabalhar a informação no contexto da saúde.

Abrange de forma sistemática a discussão no campo metodológico da produção de pesquisa na área de gestão em saúde.

Organiza a discussão em torno da concepção de sujeito, de participação, de ação e promoção do espaço democrático no interior da sociedade.
Organizar o trabalho de acordo com a estrutura hierárquica da organização do sistema de saúde vigente.

Interp retar e aplicar a legislação

referente ao sistema de saúde vigente, relacionando-o com a gestão dos serviços.

Identificar os princípios que orientam o sistema de saúde vigente.

Interp retar os códigos da informática, utilizando-os no processo de gestão.

Empregar vocabulário técnico específico da informação em saúde com os diferentes profissionais da área e com os usuários dos serviços.

Empregar o conceito de investigação científica no processo de trabalho de gestão nos serviços de saúde.

Identificar, analisar e aplicar os recursos científicos de acordo com as exigências do campo.

Identificar funções de responsabilidade no interior da equipe de trabalho.

Correlacionar formas de participação no interior das organizações de saúde.

Identificar e aplicar o exercício democrático no processo de trabalho. 
Essa estrutura permite a construção de disciplinas que discutem com maior propriedade e detalhe os fluxos da formação do técnico de gestão em serviços de saúde. Ao final do curso, o aluno é capaz de integrar e interagir como sujeito operante no espaço administrativo dos serviços de saúde, á rea meio, potencializando as mudanças que eme rgem com a descentralização e as inovações das ações de coordenação nas organizações de saúde (Abrahão, 2000).

A conformação das disciplinas para a formação do técnico de gestão em serviços de saúde, a partir dos eixos, pode ser representada pela seguinte rede curricular (Diagrama 1), em que apresentamos os eixos temáticos e as disciplinas a eles relacionadas.

Eixos temáticos e disciplinas do curso de Educação Profissional de Gestão em Serviços de Saúde

\begin{tabular}{|c|c|c|c|c|}
\hline $\begin{array}{l}\text { Administração e planejamento } \\
\text { em serviços de saúde (E1) }\end{array}$ & $\begin{array}{l}\text { Teoria Geral da } \\
\text { Administração } \\
\text { (D1) }\end{array}$ & $\begin{array}{l}\text { Informação } \\
\text { em Saúde I } \\
\text { (D3) }\end{array}$ & $\begin{array}{l}\text { Informação } \\
\text { em Saúde II } \\
\text { (D3) }\end{array}$ & $\begin{array}{l}\text { Políticas de Saúde } \\
\qquad \text { (D2) }\end{array}$ \\
\hline $\begin{array}{l}\text { Geografia espacial e política do } \\
\text { quadro sanitário brasileiro (E2) }\end{array}$ & $\begin{array}{c}\text { Direito } \\
\text { Administrativo } \\
\text { Aplicado à Gestão } \\
\text { em Saúde (D1) }\end{array}$ & $\begin{array}{c}\text { História da Ciência } \\
\text { e Tecnologia } \\
\text { (D4) }\end{array}$ & $\begin{array}{l}\text { Iniciação à } \\
\text { Pesquisa II } \\
\text { (D4) }\end{array}$ & $\begin{array}{c}\text { Novas Tecnologias } \\
\text { de Gestão } \\
\text { (D1) }\end{array}$ \\
\hline $\begin{array}{l}\text { Produção e disseminação de } \\
\text { informação em saúde (E3) }\end{array}$ & $\begin{array}{l}\text { Financiamento I } \\
\text { (D1) }\end{array}$ & $\begin{array}{l}\text { Unidades } \\
\text { Assistências de } \\
\text { Produção (D1) }\end{array}$ & $\begin{array}{l}\text { Abastecimento } \\
\text { e Pat rimônio } \\
\text { (D1) }\end{array}$ & $\begin{array}{c}\text { Avaliação dos } \\
\text { Serviços de Saúde } \\
\text { (D1) }\end{array}$ \\
\hline Ciência e tecnologia em saúde (E4) & $\begin{array}{l}\text { Informática } \\
\text { em Saúde } \\
\text { (D3) }\end{array}$ & $\begin{array}{c}\text { História dos } \\
\text { Serviços de Saúde } \\
\text { (D2) }\end{array}$ & $\begin{array}{l}\text { Financiamento II } \\
\text { (D1) }\end{array}$ & $\begin{array}{l}\text { Planejamento } \\
\text { em Saúde } \\
\text { (D1) }\end{array}$ \\
\hline Saúde, sociedade e cidadania (E5) & $\begin{array}{l}\text { Políticas Públicas } \\
\text { (D2) }\end{array}$ & $\begin{array}{c}\text { Organização } \\
\text { do Trabalho } \\
\text { (D5) }\end{array}$ & $\begin{array}{c}\text { Gestão do Trabalho } \\
\text { em Saúde } \\
\text { (D1) }\end{array}$ & $\begin{array}{l}\text { Serviços Gerais } \\
\text { (D1) }\end{array}$ \\
\hline
\end{tabular}

E - Eixotemático

D - Disciplinas relacionadas aos eixos temáticos

Pela compreensão crítica dos objetivos e pelo entendimento sobre o modo de trabalho das organizações de saúde, o técnico opera sem perder o objetivo maior que rege suas ações: o usuário. A realização das dife rentes ati- 
vidades que se concentram na área meio das organizações de saúde faz parte da formação, porém, instrumentos que visam à compreensão das atividades e as demandas originadas pelo modo de trabalho na área fim configuram uma das ferramentas mais potentes no trabalho deste profissional, que acompanha o princípio de universalização do sistema de saúde participando ativamente do processo de mudança do setor.

Criar algo novo requer mais do que simplesmente ap resentar modelos, leis e fórmulas de bons serviços de saúde. É preciso conduzir o aprendizado no sentido da reflexão e da criação de sujeitos, atores sociais co-responsáveis pelas ações desenvolvidas no interior das organizações pertinentes.

\section{Conclusão}

O desafio de formar profissionais voltados à área meio, técnicos em gestão, toma por base a geografia e política do quadro sanitário brasileiro, produção e disseminação de informação em saúde, administração e planejamento em serviços de saúde, ciência e tecnologia em saúde e saúde, sociedade e cidadania. Estes eixos se estruturam no campo da saúde coletiva e aportam competências estruturadas em um curso seqüencial, com duração de três anos.

Os eixos transversais comportam a discussão de ações para o profissional aprofundar em seu processo de trabalho uma articulação com as áreas finalísticas, subtraindo, por conseqüência, lacunas hoje existentes no processo de trabalho em saúde como um todo. Dessa forma, superam-se situações de total incompreensão entre as áreas (meio e fim), ocasionando reflexos positivos na assistência.

De forma geral, a formação de trabalhadores de gestão em serviços de saúde passa pelo campo da saúde coletiva, o que possibilita a base necessária ao desenvolvi mento e entendimento das atividades no interior das organizações de saúde. O conhecimento do processo de trabalho empregado por estes trabalhadores oferece a compreensão de novos modelos gerenciais que auxiliam na solução e condução de problemas. Para tanto, o ensino é complementado na formação do ensino médio, interligando o processo teórico e o processo prático de aprendizagem, o saber-fazer ao saber-ser e ao saberagir na área de saúde e gestão.

Mesmo neste cenário de delegação de maior responsabilidade aos níveis periféricos do sistema de saúde, permanece ainda a questão em torno da formação, configurando uma dependência dos centros formadores na apresentação de propostas que busquem articular em seu currículo elementos capazes de provocar mudanças que levem a uma descentralização responsável do sistema.

Pode-se dizer que a proposta aqui apresentada busca enfrentar essa questão, aceitando o desafio de pensar um território de conhecimento que dê ên- 
fase à formação de sujeitos capazes de integrar e interagir em seu modo de trabalho com o processo de descentralização proposto para o sistema de saúde.

Por outro lado, o novo se conforma na prática. Mas esta é complexa e precisa ser estudada com mais cuidado, percebendo-se as mensagens ap resentadas nas entrelinhas do cotidiano de uma unidade de saúde. Inovar significa repensar modos de trabalho, poderes instituídos, práticas pedagóg icas e mudanças estruturais na prática dos serviços de saúde nos quais esses novos profissionais irão atuar.

O desafio para a formação desse novo ator é colocado a cada momento. Portanto, diferentemente do que preconizava o paradigma mecanicista aquele que recorta, frag menta e esquadrinha - , busca-se hoje formar técnicos sob o olhar da complexidade e sob a ótica solidária, tentando entrar no mundo dos fluxos, da perplexidade, das sensações, para de fato se falar de mudanças.

\section{Notas}

1 Professora e pesquisadora da Escola de Enfermagem da Unive rsidade Federal Fluminense (UFF). Pesquisadora da Escola Politécnica de Saúde Joaquim Venâncio, da Fundação Oswaldo Cruz (EPSJV/Fiocruz). Doutora em Saúde Coletiva pela Universidade Estadual de Campinas (Unicamp). <analuciaabrahao@aol.com>

\section{Referências}

ABRAHÃO, Ana Lúcia S. 1999a. Habilitação em administração hospitalar: um est u d o sobre os egressos da Escola Politécnica de Saúde Joaquim Venâncio. Escola Politécnica de Saúde Joaquim Venâncio. Relatório Final do Projeto de Pesquisa "Habilitação em administração hospitalar: um estudo sobre os egressos da Escola Politécnica de Saúde Joaquim Venâncio". Rio de Janeiro: Escola Politécnica de Saúde Joaquim Venâncio, Fundação Oswaldo Cruz.

1999b. Re forma dos serviços de saúde: um olhar sobre o Hospital Público de Betim. Dissertação de Mestrado, Campinas: Faculdade de Ciências Médicas, Universidade Estadual de Campinas. 2000 .Educação profissional: administrando a competência. Relatório Final do Projeto de Pesquisa “Educação profis- 
sional: administrando a competência". Rio de Janeiro: Escola Politécnica de Saúde Joaquim Venâncio, Fundação Oswaldo Cruz.

2001. Plano de curso: Educação Profissional em Gestão de Serviços de Saúde. Rio de Janeiro: Escola Politécnica de Saúde Joaquim Venâncio, Fundação Oswa ldo Cruz. (Mimeo).

; MOURÃO, Lucia C.; GEISLER, Adriana R. R. 1999. O Hospital: um locus de aglutinação profissional. Revista Enfe rmagem Uerj, v. 7, n. 1, p. 68-72.

ALMEIDA, Célia Maria. 1999. Reforma do Estado e reforma de sistemas de saúde: experiências internacionais e tendências de mudança. Ciência e Saúde Coletiva, v. 4, n. 2, p. 263-286.

BERGER FILHO, Ruy L. 1997. Construindo a educação profissional. Brasília: Programa de Expansão da Educação Profissional, Ministério da educação. (Mimeo).

BOFF, Leonard o. 1997. A águia e a galinha: umametá fora da condição humana. Petrópolis: Vozes.

BRASIL. 1996. Lei no. 9.394, de 20 de dezembro de 1996. Estabelece as Diretrizes e Bases da Educação Nacional.

1997. Decreto no. 2.208, de 17 de abril de 1997. Regulamenta o $\S 2^{\circ}$ do art. 36 e os art. 30 a 42 da lei no. 9.394 , de 20 de dezembro de 1996, que estabelece as Diretrizes e Bases da Educação Nacional.

CAMPOS, Anna Maria. 1997. Contribuição para o resgate da relevância do conhecimento para a administração. Physis: Revista de Saúde Coletiva, v. 7, n. 2, p. 105-128.

CAMPOS, Gastão Wagner de S. 1991. A saúde pública e a defesa da vida. São Paulo: Hucitec.

1992. Reforma da reforma: repensando a saúde. São Paulo: Hucitec. 1998. O Anti-Taylor: sobre a invenção de um método para co-governar instituições de saúde produzindo liberdade e compromisso. Cadernos de Saúde Pública, v. 14, n. 4, p. 863-870.

.2000. Um método para análise e co-gestão de coletivos: a constituição de sujeitos, a produção de valores de uso e a democracia em instituições: o método da ro- da. Tese de Livre Docência, Campinas: Faculdade de Ciências Médicas, Universidade Estadual de Campinas.

DEMO, Pedro. 1991. Avaliação qualitativa. São Paulo: Cortez.

DUSSAULT, Gilles. 1992. A gestão dos serviços de saúde: características e exigências. Revista de Administração Pública, v. 26, n. 2, p. 35-45.

FERRETTI, Celso Joã o. 1997. Profissional e reforma do ensino técnico no Brasil: anos 90. Educação \& Sociedade, v. 18, n. 59, p. 225-269.

GERSCHMAN, Silvia; VIANNA, Maria Lucia W. (org s.). 1997. A miragem da pósmodernidade: democracia e políticas sociais no contexto da globalização. Rio de Janeiro: Ed. Fiocruz.

GONÇALVES, Ricardo Bruno M. 1994. Tecnologia e organização social das práticas de saúde. São Paulo: Hucitec/Associação Brasileira de Pós-Graduação em Saúde Coletiva.

GONZALES, Wânia R. C. 1996. Competência: uma alternativa conceitual? Rio de Janeiro: Confederação Nacional da Indústria.

GROSSI, Ester. 1997. Lei de Diretrizes e Bases da Educação: lei no. 9.394, de dezembro de 1996. Rio de Janeiro: Pargos.

HORTALE, Virginia A.; CONILL, Eleonor M.; PEDROZA, Manoela. 1999. Desafios na construção de um modelo para análise comparada da organização de serviços de saúde. Cadernos de Saúde Publica, v. 15, n. 1, p. 79-88.

IRIGOIN, Maria E. 1996. En torno al concepto de competencias. Lima: Ministério da Saúde (Peru). (Mimeo).

1997. Alverno College: un trabajo académico dife rente. Cidade do México: Calidad en la Educación.

KONH, Ruth C. 1994. La Notion de filets. In: CHARLOT, Bernard (coord.). L' école et le territoire: espaces, nouveaux enjeux. Paris: Armand Collin.

LEMOS, Sheila. 1994. O processo de definição e implementação de objetivos numa organização pública de saúde: o conjunto sanatorial de Curicica ao Hospital de clínicas básicas Raphael de Paula Souza. Diss e rtação de Mestrado, Rio de Janeiro: Esco- 
la Brasileira de Administração Pública de Empresas, Fundação Getúlio Vargas.

MACHADO, Lucilia Regina de S. 1998. Educação básica, empre gabilidade e competência. Trabalho \& Educação, n. 3, p. 15-31.

MÉDICI, André Cezar. 1994. Economia e financiamento do setor saúde no Brasil. São Paulo: Faculdade de Saúde Pública, Universidade de São Paulo.

MEC (Ministério da Educação). 1998. Resolução no. 3, de 26 de junho de 1998. Institui as Diretrizes Curriculares Nacionais para o Ensino Médio.

. 1999a. Parecer no. 16, de 5 de outubro de 1999. Institui as Diretrizes Curriculares Nacionais para a Educação Profissional de Nível Técnico.

1999b. Resolução no. 4, de 8 de novembro de 1999. Institui as Diretrizes Curriculares Nacionais para a Educação Profissional de Nível Técnico.

MENDES, Eugênio V. (org.). 1998. Organização da saúde no nível local. São Paulo: Hucitec.

MERHY, Emerson Elias. 2002. Saúde: a cartografia do trabalho vivo. São Paulo: Hucitec.

MINAYO, Maria Cecília de S. 1993. O desafio do conhecimento: pesquisa qualitativa em saúde. São Paulo: Hucitec.

MINTZBERG, Henry. 1995. C riando organizações eficazes:estruturas em cinco configurações. São Paulo: Atlas.

MS (Ministério da Saúde). Portaria no. 2.203, de 5 de nove mbro de 1996. Dispõe sobre a Norma Operacional Básica do SUS $01 / 96$.

MTb (Ministério do Trabalho). 1996. Habilidades, questão de competências? Brasília: Secretaria de Formação e Desenvolvimento Profissional, Ministério do Trabalho/
Conselho Deliberativo, Fundo de Amparo ao Trabalhador.

NASCIMENTO NETO, Antenor. 1996. O que é a globalização, o que provoca medo e o que se pode esperar dela. Veja, 3 abr., n. 14 , p. $80-89$.

RIVERA, Francisco J. U. 2003. Análise estratégica em saúde e gestão pela escuta. Rio de Janeiro: Ed. Fiocruz.

SANTOS, Isabel; CHRISTÓFARO, Maria Auxiliadora C. 1996. A formação do trabalhador da área de saúde. Divulgação em Saúde para Debate, n. 14, p. 48-52.

SAVIANI, Nereide. 1994. Saber escolar, currículo e didática: problemas da unidade conteúdo-método no processo pedagógico. Campinas: Autores Associados.

SOUZA, Donaldo B. de. 1996. Globalização: a mão invisível do me rcado mundializada nos bolsões da desigualdade social. Boletim Técnico do Senac, v. 22, n. 2. Disponível em: <www.senac.br/informativo/ BTS/222/boltec222a.htm>. Acesso em: 28 jul. 2005.

VIANA, Ana Luíza. 1997. As políticas sociais e as políticas de saúde no contexto do processo de globalização. In: GERSCHMA N, Silvia; VIANNA, Maria Lucia W. (orgs.). A miragem da pós-modernidade: democracia e políticas sociais no contexto da globalização. Rio de Janeiro: Ed. Fiocruz, p.19-34.

TANAKA, Oswaldo Y. et al. 1999. Formação de gestores locais: processos para identificar estratégias de atuação. Revista de Saúde Pública, v. 33, n. 3, p. 219-229.

TANGUY, Lucia; ROPÉ, Françoise (orgs.). 1997. Saberes e competências: o uso de tais noções na escola e na empresa. Campinas: Papirus.

Recebido em 28/03/2005

Aprovado em 09/06/2005 